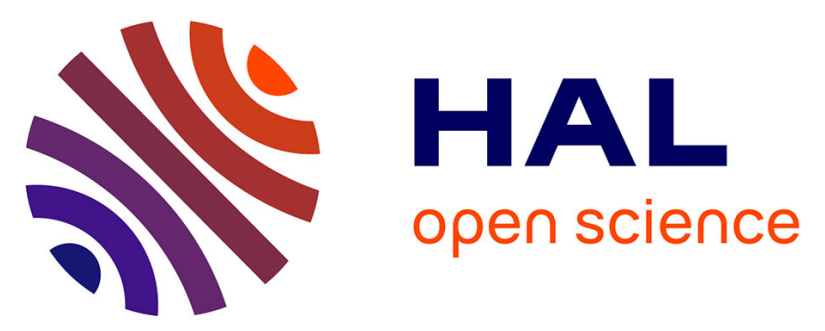

\title{
SMALL VOLUME LONG PULSE X RAY PREIONISED XeCl LASER WITH DOUBLE DISCHARGE AND FAST FERRITE MAGNETIC SWITCH
}

J. Hueber, M. Kobhio, B. Fontaine, Ph. Delaporte, M. Sentis, B. Forestier

\section{To cite this version:}

J. Hueber, M. Kobhio, B. Fontaine, Ph. Delaporte, M. Sentis, et al.. SMALL VOLUME LONG PULSE X RAY PREIONISED XeCl LASER WITH DOUBLE DISCHARGE AND FAST FERRITE MAGNETIC SWITCH. Journal de Physique IV Proceedings, 1991, 01 (C7), pp.C7-567-C7-570. 10.1051/jp4:19917151 . jpa-00250826

HAL Id: jpa-00250826 https://hal.science/jpa-00250826

Submitted on 1 Jan 1991

HAL is a multi-disciplinary open access archive for the deposit and dissemination of scientific research documents, whether they are published or not. The documents may come from teaching and research institutions in France or abroad, or from public or private research centers.
L'archive ouverte pluridisciplinaire HAL, est destinée au dépôt et à la diffusion de documents scientifiques de niveau recherche, publiés ou non, émanant des établissements d'enseignement et de recherche français ou étrangers, des laboratoires publics ou privés. 


\title{
SMALL VOLUME LONG PULSE X RAY PREIONISED XeCI LASER WITH DOUBLE DISCHARGE AND FAST FERRITE MAGNETIC SWITCH
}

\author{
J.M. HUEBER, M.N. KOBHIO, B.L. FONTAINE, Ph. DELAPORTE, M. SENTIS and \\ B.M. FORESTIER
}

IMFM-UM34 CNRS, Aix-Marseille University, 1 rue Honnorat, F-13003 Marseille, France

\begin{abstract}
Experimental results obtained with a high efficiency small volume long pulse $X$-Ray preionised $\mathrm{XeCl}$ laser with double discharge and very fast ferrite magnetic switch are presented and compared with the results given by a new $\mathrm{XeCl}$ laser numerical self consistant model.The model takes into account most recent kinetic data and time variation of discharge impedence and switch inductance. There is a good agreement beetwen experiment and model on electrical and laser parameters for typical conditions.
\end{abstract}

\section{1.- Introduction}

Potential applications of high power pulsed ultraviolet lasers have recently stimulated considerable interest in the scaling of excimer lasers to higher output energy, pulse length, pulse repetition frequency, average laser power and efficiency $(1)$. Discharge pumped excimer lasers are extensively used in various domains of scientific research and industrial processing. Recent developments of long pulse high efficiency self sustained discharge excimer lasers provide a number of opportunities in terms of lower stress on electrical components, lower heat and acoustic load by extracted photon, higher energy transmission capability through optical fiber, and better control of laser beam divergence, polarization and line-width (2)-(5).

A program to extensively investigate the key parameters which may limit scaling of the $\mathrm{XeCl}$ laser $(\lambda=308 \mathrm{~nm})$ to very high average power $\left(P_{1} \approx 1 \mathrm{kw}\right)$ has been undertaken at IMFM $(6)(7)$. This program includes theoretical, numerical and experimental studies of possible advanced excitation schemes in order to increase both laser pulse length and whole system efficiency.

This paper presents results of a parametric experimental and numerical study of a small volume long pulse $\mathrm{X}$-ray preionized $\mathrm{XeCl}$ laser using double discharge with a fast ferrite magnetic switch. This system allows both long pulse, high efficiency and high PRF capabilities $(\approx 1 \mathrm{KHz})$.

\section{2.- Experimental set-up}

The experimental set-up ${ }^{(8)}$ has allowed high efficiency $\mathrm{X}$-ray preionized discharge $\mathrm{XeCl}$ laser excitation with a $\mathrm{Ne} / \mathrm{Xe} / \mathrm{HCl}$ mixture in a $50 \mathrm{~cm} 3$ active volume $\left(25^{\star} 2^{\star} 1 \mathrm{~cm} 3\right)$ at relatively low pressure $(2,5 \mathrm{~atm}$.).A Shematic diagram of laser electrical circuit is shown on fig 1 . A fast high voltage (30-40 KV) and low energy spiker pulse is applied across laser electrodes to initiate an uniform discharge. Peaking capacitors are set in a low inductance configuration. Main discharge is energized by a 100-200ns electrical time pulse charged double sided solid state PFL of much lower voltage (5-10 KV ) which is automatically applied to electrodes through a low inductance path after magnetic switch saturation by spiker current. The magnetic switch is made of several coaxial structures set in parallel, each of them including many high frequency $\mathrm{Ni}-\mathrm{Zn}$ ferrite tores in serie. 


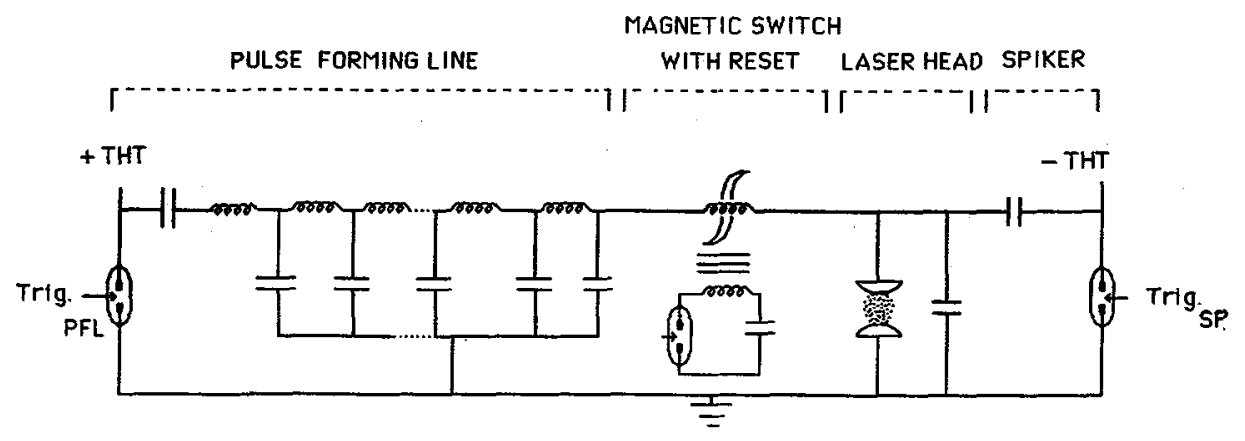

Fig. 1 : Shematic diagram of double discharge laser electrical circuit.

\section{3.- XeCl laser numerical model}

A complete self-consistent model of long pulse $\mathrm{XeCl}$ excimer laser excited by a double discharge with fast ferrite magnetic switch has been established at IMFM for a $\mathrm{Ne} / \mathrm{Xe} / \mathrm{HCl}$ active medium $(9),(10)$. The model organization is shown schematically in Fig. 2. Model includes rate equations for 23 species with most recent available rate constant values for 72 reactions $(11)$, circuit equations with time dependant ferrite switch inductance and plasma impedance and rate equation for laser emission taking into account absorptions. The model takes into account delay time beetwen spiker and sustainer, low value of sustainer field and dynamics of magnetic switch.

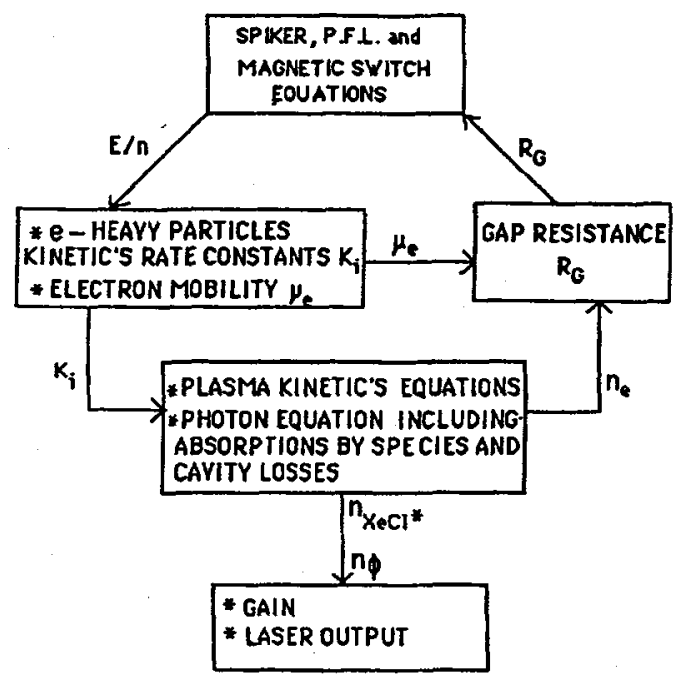

Fig 2 : Numerical model organisation.

\section{Results}

A small volume long pulse $\mathrm{X}$-ray preionised $\mathrm{XeCl}$ laser with double discharge and fast ferrite magnetic switch as been studied. The effects of ferrite material has been taken into account. An efficiency of $3,2 \%$ in energy and $4 \%$ in power at the maximum with up to $150 \mathrm{~mJ}$ extracted optical energy in a 130 ns (FWHM) laser pulse length, has been demonstrated experimentally, for single shot conditions, with this not optimized device ${ }^{(8)}$. 
Comparison between numerical modeling and experimental results with the I.M.F.M.set-up shows, for various PFL charge voltage conditions, a good quantitative agreement for electrical parameters behavior as well as for laser power and energy. Fig. 3 shows calculated and experimental electrical and optical waveforms for a sustainer voltage of $7 \mathrm{KV}$ and a magnetic switch made of two coaxial structures set in parallel $(\mu=200)$. Model simulates very well spiker-sustainer delay time as well as time needed to reach lasing threshold and laser pulse length. Difference between computed and measured values of laser energy, for same working conditions, is typically $30 \%$.

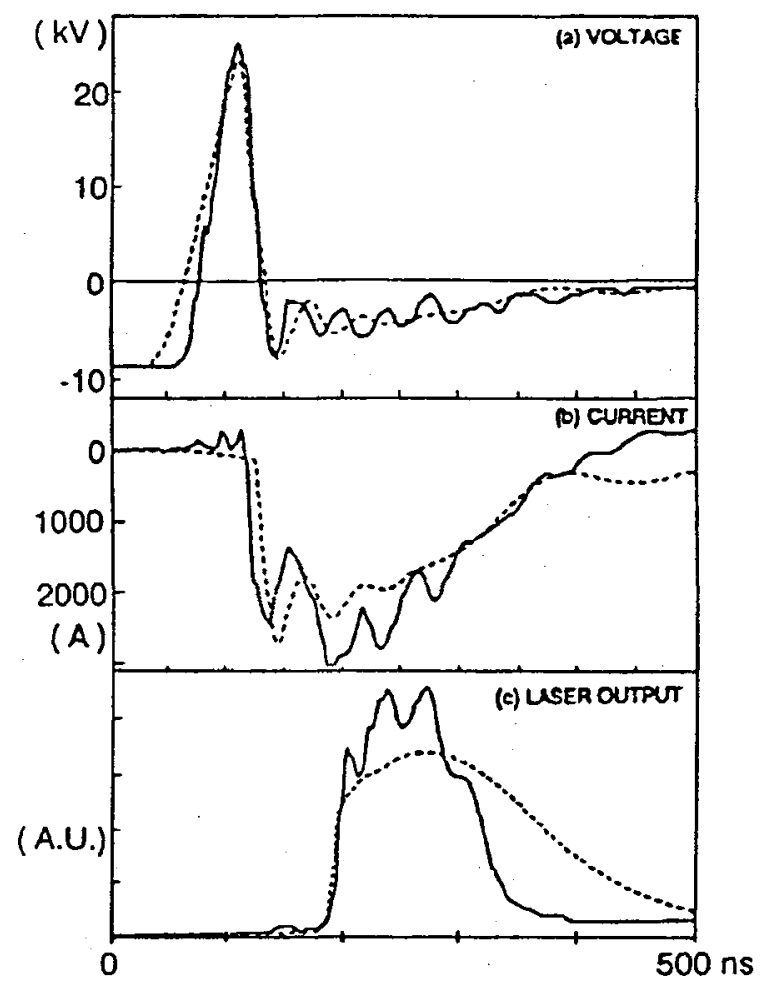

Fig 3 : calculated and experimental waveform of (a) time variation of magnetic switch voltage, (b) current through the switch and (c) laser emission.

A parametric study of the $\mathrm{XeCl}$ laser with double discharge and magnetic switch has been fulfilled as well as a comparison with both experiments and numerical results of excitation by a C-L-C classical circuit for the same geometric and gas conditions and the same imput energy. As an exemple a comparison of calculated laser power and gain for double discharge and C-L-C discharge excitation is shown in Fig. $4\left(W_{\text {el }}=6,8\right.$ joules). One observes that for C-L-C excitation initial gain is much higher and of much shorter duration than for double discharge. Laser pulse is very short (40 ns to be compared to $150-200$ ns for double discharge excitation) and does not reach stationnary conditions. It is important to note that electrical energy added to active medium is typically $50 \%$ of stored energy for the C-L-C case and $85 \%$ for the double discharge case. 

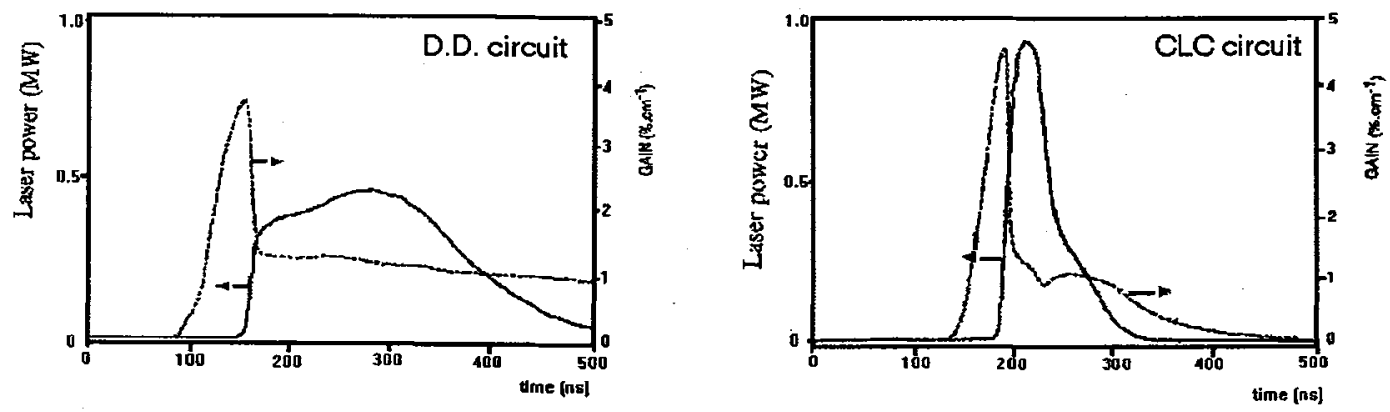

Fig 4: Calculated laser power and gain for double discharge and C-L-C discharge excitation systems.

\section{5.- Conclusion}

The present study shows a good agreement beetwen experiments and a new model developped at IMFM for small volume long pulse $\mathrm{X}$-ray preionised $\mathrm{XeCl}$ laser with double discharge and fast magnetic switch.

Future experimental and numerical work is planned at IMFM on $\mathrm{XeCl}$ laser with double discharge and magnetic switch, in the frame of EUREKA EU 205 program (Eurolaser-excimer lasers ), with the aim to optimize such a laser in terms of energy per pulse and efficiency. Experimental part of this study will be made on LUX test:bed for conditions of very high average power $\left(P_{1} \approx 100-1000 \mathrm{~W}\right)$ and repetition rate (PRF $>1 \mathrm{khz})(6)(7)$.

\section{6.- Acknowledgments}

This research was supported in part by french Ministry of Research in the frame of EUREKA EU205 Program and by french DRET.

\section{References}

1. See, for example, papers on $\mathrm{XeCl}$ lasers in Technical Digests, Conference on Lasers and Electrooptics (Optical Society of America, Washington, DC, 1985-1991).

2. W.H. Long Jr, M.J. Plummer and E. Stappaert, Appl. Phys. Lett. 43, 735 (1984).

3. C.A. Fisher, M.J. Kushner, T.E. Dehart, J.P. Daniel, R.A. Petr and J.J. Ewing, Appl. Phys. Lett. 48 , 1574 (1986).

4. R.S. Taylor and K.E. Leopold, J. Appl. Phys., 65, 22 (1989)

5. T.J. McKee, G. Boyd and T.A. Znotin, IEEE Photonics Technology Lett. PTL1, 59 (1989)

6. M.L. Sentis, Ph. Delaporte, B.M. Forestier and B.L. Fontaine, J. Appl. Phys. 66, 1925 (1989)

7. M.L. Sentis, Ph. Delaporte, B.M. Forestier and B.L. Fontaine, IEEE J. Quant. Electr., to be published (1991)

8. J.M. Hueber, B.L. Fontaine, B.M. Forestier, Ph. Delaporte, M. Sentis, Opt. Comm., to be published (1991)

9. M.N. Kobhio, Thesis, Aix-Marseille University. (1990)

10. M.N. Kobhio, B. L. Fontaine, J.M. Hueber, Ph. Delaporte, B.M. Forestier, and M.L. Sentis, E.C.O.4, The Hague, Mars 1991, SPIE Vol 1503, 1991

11. W. Bottitcher, invited paper, Xth ESCAMPIG, Orleans (1990), Pr. Europhysics Conf. Abstr., 8 (1990) 